\title{
Polysaccharide CM1 from Cordyceps militaris hinders adipocyte differentiation and alleviates hyperlipidemia in $\mathrm{LDLR}^{(+/-)}$ hamsters
}

Wen-Qian Yu', Fan Yin ${ }^{\dagger}$, Nuo Shen, Ping Lin, Bin Xia, Yan-Jie Li ${ }^{*}$ and Shou-Dong Guo (1)

\begin{abstract}
Background: Cordyceps militaris is cultured widely as an edible mushroom and accumulating evidence in mice have demonstrated that the polysaccharides of Cordyceps species have lipid-lowering effects. However, lipid metabolism in mice is significantly different from that in humans, making a full understanding of the mechanisms at play critical.

Methods: After 5 months, the hamsters were weighed and sampled under anesthesia after overnight fasting. The lipid-lowering effect and mechanisms of the polysaccharide CM1 was investigated by cellular and molecular technologies. Furthermore, the effect of the polysaccharide $\mathrm{CM} 1(100 \mu \mathrm{g} / \mathrm{mL})$ on inhibiting adipocyte differentiation was investigated in vitro.

Results: CM1, a polysaccharide from C. militaris, significantly decreased plasma total cholesterol, triglyceride and epididymal fat index in $\mathrm{LDLR}^{(+-)}$hamsters, which have a human-like lipid profile. After 5 months' administration, CM1 decreased the plasma level of apolipoprotein B48, modulated the expression of key genes and proteins in liver, small intestine, and epididymal fat. CM1 also inhibited preadipocyte differentiation in 3T3-L1 cells by downregulating the key genes involved in lipid droplet formation.

Conclusions: The polysaccharide CM1 lowers lipid and adipocyte differentiation by several pathways, and it has potential applications for hyperlipidemia prevention.
\end{abstract}

Keywords: Polysaccharide, Hyperlipidemia, Lipid homeostasis, NPC1L1, Adipocyte

\section{Background}

Hyperlipidemia is a pathogenic factor for cardiovascular disease (CVD) [1-3]. Presently, cholesterol-lowering drugs, such as statins and proprotein convertase subtilisin/kexin type 9 (PCSK9) antibodies, play important roles in prevention and treatment of CVD [1-3].

\footnotetext{
*Correspondence: liyj@wfmc.edu.cn; SD-GUO@hotmail.com

${ }^{+}$Wen-Qian Yu and Fan Yin contributed equally to this work.

Institute of Lipid Metabolism and Atherosclerosis, Innovative Drug Research Centre, School of Pharmacy, Weifang Medical University, Baotongxi street 7166\#, Weifang, Shandong province, China
}

Furthermore, ezetimibe has been developed to inhibit cholesterol reabsorption in the gut lumen by targeting Niemann-Pick C1-like 1 (NPC1L1) [4-6]. However, the currently deployed lipid-lowering drugs are unable to completely retard the progression of CVD. In more recent years, significant research has been conducted aimed at utilizing natural compounds in food for the same purposes, due to their potentially lower toxicity levels.

The edible fungus Cordyceps militaris is a commercialized mushroom that primarily consumed in Asian

(c) The Author(s). 2021 Open Access This article is licensed under a Creative Commons Attribution 4.0 International License, which permits use, sharing, adaptation, distribution and reproduction in any medium or format, as long as you give appropriate credit to the original author(s) and the source, provide a link to the Creative Commons licence, and indicate if changes were made. The images or other third party material in this article are included in the article's Creative Commons licence, unless indicated otherwise in a credit line to the material. If material is not included in the article's Creative Commons licence and your intended use is not permitted by statutory regulation or exceeds the permitted use, you will need to obtain permission directly from the copyright holder. To view a copy of this licence, visit http://creativecommons.org/licenses/by/4.0/ The Creative Commons Public Domain Dedication waiver (http://creativecommons.org/publicdomain/zero/1.0/) applies to the data made available in this article, unless otherwise stated in a credit line to the data. 
countries [7-9], and it is often used as a soup ingredient in South China. This region of China also has a lower mortality of atherosclerotic CVD per 100,000 compared with that of North China (65.0 vs 121.2) [1]. Although there is no direct evidence that the fruiting body of $C$. militaris can decrease atherosclerotic CVD in humans, a significant amount of evidence in mice has demonstrated that the water extracts of Cordyceps species have various bioactivities, including anti-hyperlipidemia and antiatherosclerosis effects [8-10]. Based on the available data, the crude extracts rather than purified polysaccharides of Cordyceps species are generally used in the previous in vivo studies [11-14]. Furthermore, lipid metabolism in mice is different from that of humans, primarily due to the lack of cholesteryl ester transfer protein (CETP) in mice and distinct apolipoprotein (apo) B editing [15]. Additionally, the treatment time in the previous studies is generally less than 2 months. As hyperlipidemia needs a long-term intervention, it is necessary to clarify the lipid-lowering effects and mechanisms of these polysaccharides in animals whose lipid profiles are closer to humans based on a longer intervention time.

Hamsters have CETP and a low level of hepatic cholesterol synthesis similar to those seen in humans, making them excellent models for studies involving lipid metabolism [15]. Recently, researchers successfully established low-density lipoprotein receptor (LDLR)-deficient $(\mathrm{LDLR})^{(--)}$and heterozygous LDLR-deficient $\left(\operatorname{LDLR}^{(+/-)}\right)$hamster models, which have an autosomal inherited hypercholesterolemia $[4,15]$. Hepatic LDLR is mainly responsible for the clearance of apoB-containing particles in circulation [16], making $\operatorname{LDLR}^{(+/-)}$hamsters ideal for studying bioactive compounds with antihyperlipidemic activities. In a previous study, the polysaccharide CM1, mainly consisted of $\rightarrow 4)-\beta$-D-Glc $p$ $(1 \rightarrow$ and $\rightarrow 2)-\alpha-$ D-Man $p(1 \rightarrow$ glycosyls (Fig. 1$)$, with cholesterol efflux promoting activity was purified from the fruiting body of C. militaris [17]. In this study, $\mathrm{LDLR}^{(+/)}$hamsters, whose lipid profiles are similar to those seen in humans, were used to explore the effect of long-term treatment of CM1 in attenuating hyperlipidemia and regulating lipid metabolism-related genes and proteins.

\section{Materials and methods Materials}

CM1 was obtained from $C$. militaris as the previously described method (Fig. 1A and B) [17]. Ezetimibe was the product of Selleck (Shanghai, China). The murine 3T3-L1 cell line was bought from National Collection of Authenticated Cell Cultures (Shanghai, China). Dexamethasone, 3-isobutyl-1-methylanxthine, and insulin were the products of Sigma-Aldrich (St. Louis, MO,
USA). Dulbecco's modified Eagle's medium (DMEM) and fetal bovine serum (FBS) were the products of Thermo Fisher Biochemical Products (Beijing) Co. Ltd. (Beijing, China). Assay kits for lipid analysis and lipoprotein lipase (LPL) activity were obtained from Biosino Bio-technology and Science Inc. (Beijing, China). Lipofectamine RNAiMAX was bought from Invitrogen (Lot: 2164333, CA, USA). Opti-MEM was obtained from Gibico (Grand Island, NY, USA). Hematoxylin and eosin working solutions were bought from Nanchang YULU Laboratory Equipment Co., Ltd. (Jiangxi, China).

\section{Cell culture and treatment}

Cells were cultured as the previously described method [18]. At day one, cells were set in six-well dishes at a density of $2 \times 10^{5}$ cells per well. At day two, cells were separated into different groups: blank, differentiated, and CM1 group $(100 \mu \mathrm{g} / \mathrm{mL})$. The in vitro dosage of CM1 was determined according to the previous studies [17, 19]. The cells in the blank group were treated with the basal medium, and the medium was changed every $48 \mathrm{~h}$. The cells in the differentiated group and CM1 group were treated with differentiation medium I (basal medium containing $4.0 \mu \mathrm{g} / \mathrm{mL}$ insulin, $0.5 \mathrm{mM} \quad 3-$ isobutyl-1-methylanxthine, and $1.0 \mu \mathrm{M}$ dexamethasone) and differentiation medium I plus CM1, respectively, for 2 days. At day four, the cells, except for the blank group, were treated with differentiation medium II (basal medium containing $4.0 \mu \mathrm{g} / \mathrm{mL}$ insulin) and differentiation medium II plus CM1, respectively, for 2 days. At day six, the medium in each group was changed to the basal medium. At day eight, cells were labeled with BODIPY (493/505) or collected for quantitative RT-PCR analysis. For in situ staining, cells were labeled with $1.0 \mu \mathrm{M}$ BODIPY [20].

Furthermore, 3T3-L1 cells that seeded in six-well dishes were transfected with peroxisome proliferatoractivated receptor (PPAR) $\alpha$ siRNA (target sequence: $5^{\prime}$ GGAGCATTGAACATCGAAT-3'). The target sequence for scrambled siRNA was not provided by the company due to patent protection. Cells were transfected with scrambled or PPAR $\alpha$ siRNAs $(10 \mathrm{nM})$ using Lipofectamine RNAiMax ( $3 \mu \mathrm{L}$ per well) that dissolved in Opti-MEM according to the instruction. Cells were then treated with or without CM1 $(100 \mu \mathrm{g} / \mathrm{mL})$ for another $24 \mathrm{~h}$.

\section{Animal grouping and treatment}

This study was approved by Weifang Medical University (2020SDL106-3). Twenty $\mathrm{LDLR}^{(+-)}$hamsters (male, $152 \pm 14 \mathrm{~g}$ ) were provided by Peking University (Beijing, China). As a bioactive macromolecule, CM1 may affect the gut system rather than directly act on the circulation. Therefore, ezetimibe, a lipid-lowering drug which acts 


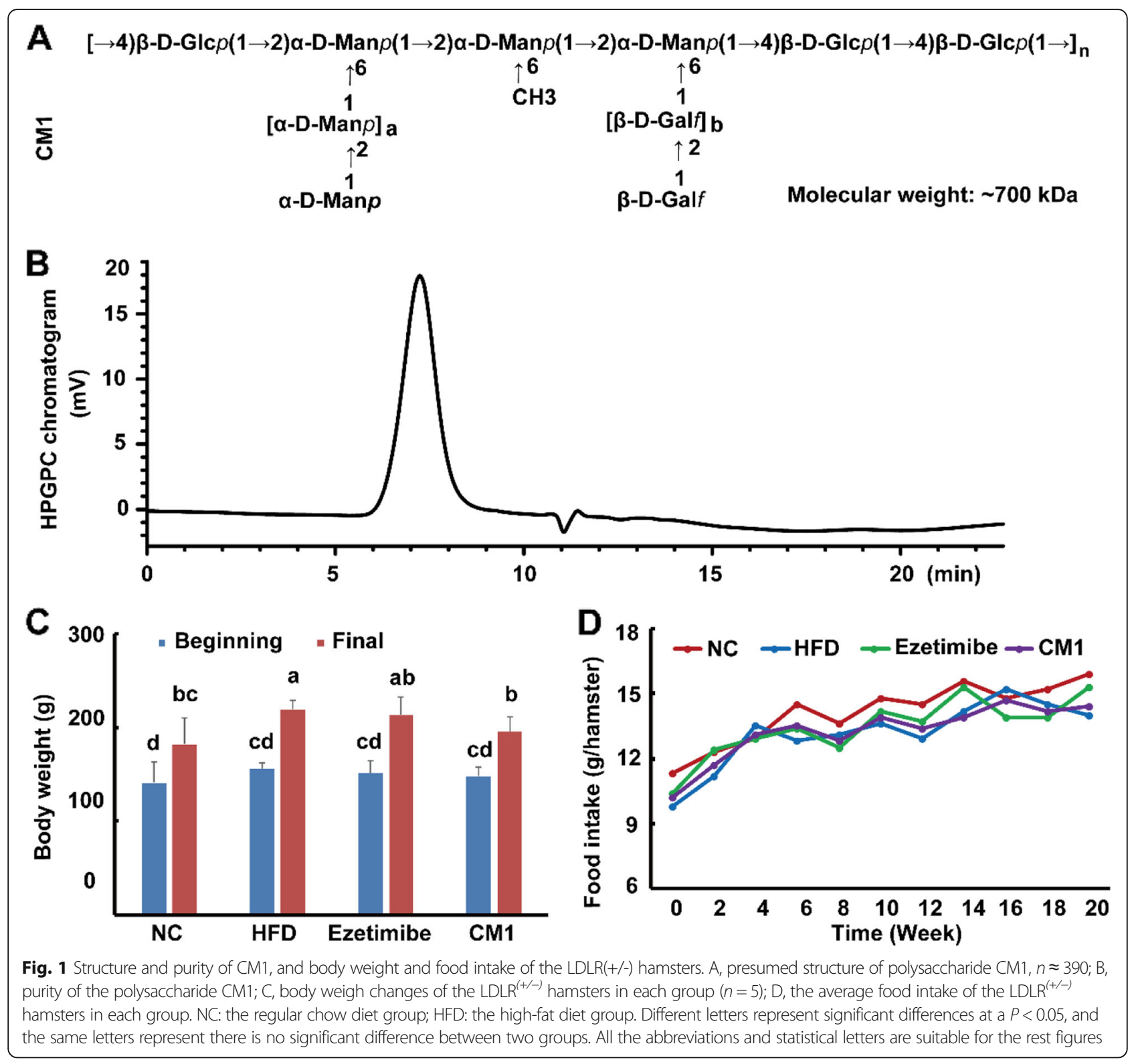

on the internalization of NPC1L1 in intestine $[5,6]$, was used as a positive control. Except for the regular chow (NC) group, $\operatorname{LDLR}^{(+/-)}$hamsters in the high-fat diet group (HFD), the ezetimibe group $(25 \mathrm{mg} / \mathrm{kg} / \mathrm{d})$, and the CM1 group (CM1, $100 \mathrm{mg} / \mathrm{kg} / \mathrm{d}$ ) were fed a high-fat diet ( $0.15 \%$ cholesterol). The dosages of ezetimibe and CM1 were determined according to the available purified polysaccharide and the previous studies $[4,10,21]$. After 5 months, the hamsters were weighed and sampled under anesthesia after overnight fasting.

\section{Plasma analysis}

Blood was collected from each hamster using heparinized capillary tubes and centrifugated to obtain plasma. Total cholesterol (TC) and triglyceride (TG) levels and
LPL activity in the post-heparin plasma were assayed, and the lipid profiles of the lipoproteins were evaluated via the previous method [10].

\section{Hematoxylin and eosin staining}

The embedded epididymal fat in Optimal Cutting Temperature Compound was cut and stained using the previous method [22].

\section{Real-time quantitative PCR (RT-qPCR)}

Total RNAs were prepared via the Trizol method. The primers of the interested genes were listed in Table 1. RT-qPCR was performed as described in the previous study [18]. Relative gene expression was normalized to glycer-aldehyde-3-phosphate dehydrogenase (GAPDH) 
Table 1 The primers used for the polymerase chain reaction $(\mathrm{PCR})$ reaction

\begin{tabular}{|c|c|c|}
\hline Primer & & Sequences $\left(5^{\prime}-3^{\prime}\right)$ \\
\hline GAPDH & Forward & СTCCCACTCTTCCACCTTTGATGC \\
\hline hamster & Reverse & GTCCACCACTCTGTTGCTGTAGC \\
\hline SREBP-2 & Forward & GCTACTTCCTTAATCGTGCCCAGAG \\
\hline hamster & Reverse & TCCTTGGCTGCTGACTTGATTGAC \\
\hline SREBP-1C & Forward & GCGGACGCAGTCTGGG \\
\hline hamster & Reverse & ATGAGCTGGAGCATGTCTTCAAA \\
\hline ABCG8 & Forward & TGCTGGCCATCATAGGGAG \\
\hline hamster & Reverse & TCCTGATTTCATCTTGCCACC \\
\hline LDLR & Forward & GCCGGGACTGGTCAGATG \\
\hline hamster & Reverse & ACAGCCACCATTGTTGTCCA \\
\hline LXRa & Forward & GCAGGACCAGCTCCAAGTAG \\
\hline hamster & Reverse & GCAGGACCAGCTCCAAGTAG \\
\hline PCSK9 & Forward & TGCTCCAGAGGTCATCACAG \\
\hline hamster & Reverse & GTCCCACTCTGTGACATGAAG \\
\hline CYP7A1 & Forward & GGTAGTGTGCTGTTGTATATGGGTTA \\
\hline hamster & Reverse & ACAGCCCAGGTATGGAATCAAC \\
\hline GAPDH & Forward & AGGTCGGTGTGAACGGATTTG \\
\hline mouse & Reverse & GGGGTCGTTGATGGCAACA \\
\hline PPARa & Forward & AACATCGAGTGTCGATATTGTGG \\
\hline mouse & Reverse & CCGAATAGTTCGCCGAAAGAA \\
\hline PPARY & Forward & TCGCTGATGCACTGCCTATG \\
\hline mouse & Reverse & GAGAGGTCCACAGAGCTGATT \\
\hline FAS & Forward & CATCCACTCAGGTTCAGGTG \\
\hline mouse & Reverse & AGGTATGCTCGCTTCTCTGC \\
\hline ACC1 & Forward & GAGGTACCGAAGTGGCATCC \\
\hline mouse & Reverse & GTGACCTGAGCGTGGGAGAA \\
\hline SCD1 & Forward & CATCATTCTCATGGTCCTGCT \\
\hline mouse & Reverse & CCCAGTCGTACACGTCATITI \\
\hline DGAT1 & Forward & TGGTGTGTGGTGATGCTGATC \\
\hline mouse & Reverse & GCCAGGCGCTTCTCAA \\
\hline DGAT2 & Forward & GGCTACGTTGGCTGGTAACT \\
\hline mouse & Reverse & CACTCCCATTCTTGGAGAGC \\
\hline
\end{tabular}

and calculated according to the $2^{-\Delta \Delta C t}$ formula. GAPDH is a glycolytic enzyme and is widely used as an internal reference [23]. High-fat diet may alter the glycolytic activity, therefore, the gene expression in ezetimibe and CM1 groups were compared to the HFD group to reduce the potential effects of diet.

\section{Immunoblotting analysis}

This experiment was performed according to the previously reported methods [17-19]. For the epididymal fat samples, the lipids in the upper layer of the prepared homogenate were carefully removed after centrifugation.
Immunoblotting was carried out using primary and secondary antibodies. Mouse monoclonal antibodies were used against PPAR $\alpha$ (sc398394), $\beta$ (sc-74,517) and $\gamma$ (sc7273), NPC1L1 (sc-166,802), adipose triglyceride lipase (ATGL, sc-365,278), sterol regulatory element binding protein (SREBP)-1c (sc-13,551) and-2 (sc-271,616), apoAI (sc-58,230), and LPL (sc-373,759). A rabbit polyclonal antibody was used against LDLR (sc-18,823) (Santa Cruz, CA, USA). A rabbit polyclonal antibody was used against ATP-binding cassette $(\mathrm{ABC})$ G8 (bs10149R, Bioss, Beijing, China). A rabbit monoclonal antibody was used against scavenger receptor B type 1 (SR-B1, ab217318). A rabbit polyclonal antibody was used against liver $\mathrm{X}$ receptor (LXR) $\alpha$ (ab176323) (Abcam, MA, USA). Rabbit polyclonal antibodies were used against PCSK9 (55206-1-AP), albumin (16475-1AP), and apoB (20578-1-AP) (Proteintech, IL, USA). A mouse monoclonal antibody was used against $\beta$-actin (66009-1-Ig) (Proteintech, IL, USA). A rabbit polyclonal antibody was used against cholesterol 7- $\alpha$-hydroxylase A1 (CYP7A1, NP_000771) (OriGene, Shanghai, China).

\section{Data analysis}

All the bioassay results were expressed as mean \pm standard deviation $(S D)$ for at least three independent experiments. One-way analysis of variance (ANOVA) analysis was used to detect significant difference between any two groups with SPSS19.0 software. Different letters were considered to be statistically significant at a $P<$ 0.05 , and the same letters meant there were no significant difference between two groups.

\section{Results}

CM1 intervention alleviated hyperlipidemia

LDLR $^{(+/)}$hamsters have an autosomal inherited hypercholesterolemia $[15,24]$. The body weight of the hamsters in the NC, HFD, ezetimibe, and CM1 group increased approximately $29.1,40.4,41.0$, and $32.1 \%$, respectively, after feeding for 5 months (Fig. $1 C, P<0.01$ ). Although the average food intake had no obvious differences among groups (Fig. 1D), CM1 intervention significantly decreased the final body weight of the hamsters (Fig. 1C, $P<0.05$ ). Of note, HFD dramatically increased the average plasma TC (Fig. 2A, 128.8 vs $393.9 \mathrm{mg} / \mathrm{dL}$ ) and TG (Fig. 2B, 104.6 vs $238.5 \mathrm{mg} / \mathrm{dL}$ ) levels of the $\mathrm{LDLR}^{(+/-)}$hamsters $(P<0.01)$. In line with previous studies [4, 24], ezetimibe also significantly decreased the elevated plasma TC level by $\sim 72 \%$ and TG level by $49 \%(P<0.01)$. CM1 intervention notably decreased the plasma TC level by $\sim 28 \%$ (Fig. $2 \mathrm{~A}, P<0.05,283.2$ vs $393.9 \mathrm{mg} / \mathrm{dL}$ ) and TG level by 16\% (Fig. 2B, 201.2 vs $238.5 \mathrm{mg} / \mathrm{dL}$ ). Furthermore, CM1 intervention significantly decreased the low-density lipoprotein (LDL) and high-density lipoprotein (HDL) cholesterol levels (Fig. 

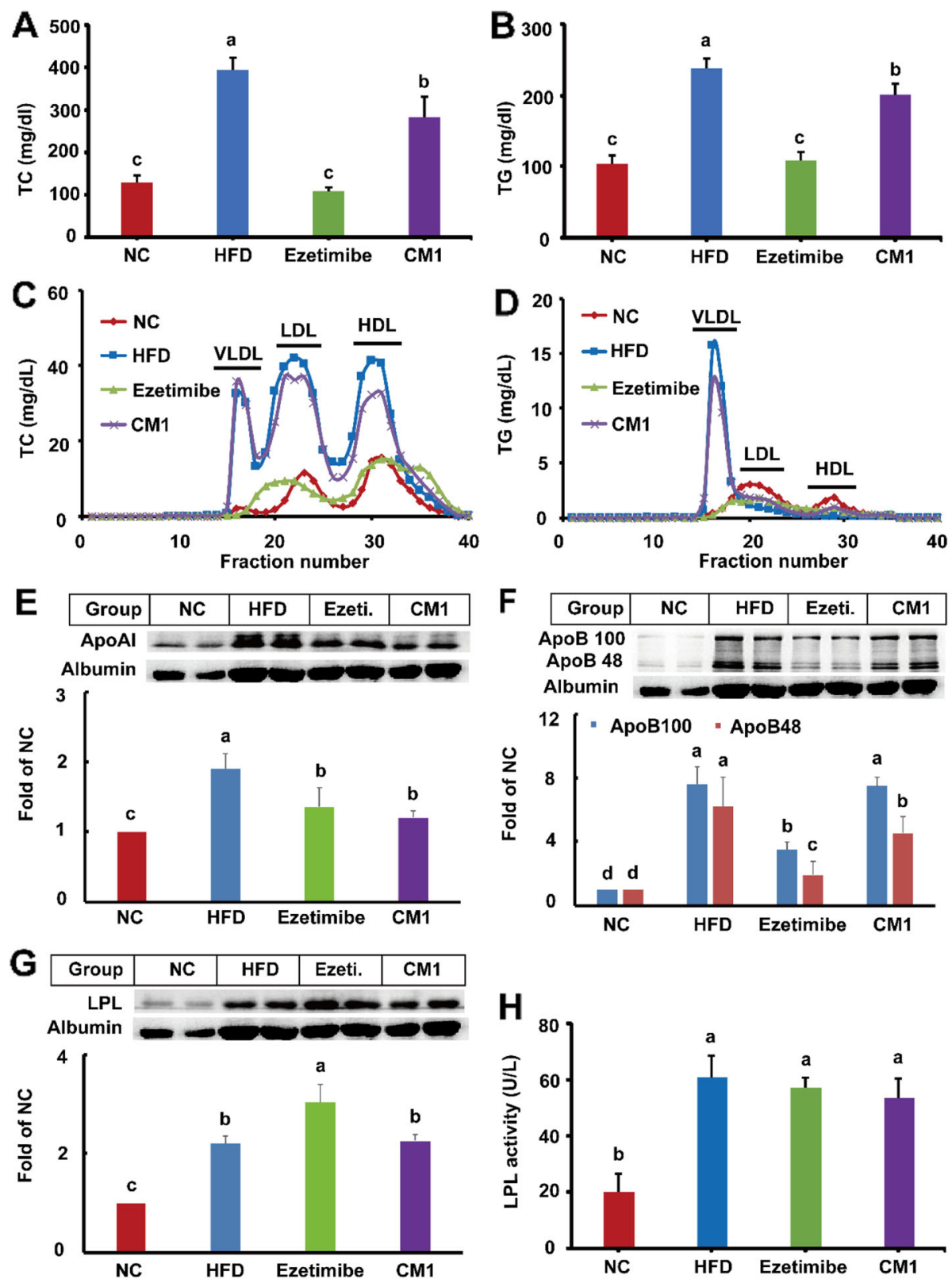

Fig. 2 Effect of $C M 1$ on the plasma lipid profiles and the expression of plasma apoAl, apoB and LPL $(n=5)$. A, plasma TC concentrations; B, plasma TG concentrations; C and D, plasma TC and TG profiles of the lipoproteins after ÄKTA-FPLC separation, respectively; E, F and G, plasma apoAl, apoB and LPL expression and densitometric quantification, respectively; $H$, plasma LPL activity. Data are presented as mean $\pm S D$. Ezetimibe (Ezeti.): hamsters treated with ezetimibe at the dose of $25 \mathrm{mg} / \mathrm{kg} / \mathrm{d}$; CM1: LDLR ${ }^{(+/)}$hamsters treated with CM1 at the dose of $100 \mathrm{mg} / \mathrm{kg} / \mathrm{d}$. All the abbreviations applied for the rest of the figures

2C). It also reduced TG level in the very low-density lipoprotein (VLDL) fractions (Fig. 2D).

In line with HDL cholesterol, HFD dramatically enhanced the plasma apoAI level (Fig. 2E, $P<0.01$ ). Of note, ezetimibe and CM1 intervention decreased the elevated plasma apoAI level by approximately $29 \%$ and $36 \%$, respectively (Fig. 2E, $P<0.05$ ). Hamsters have both apoB100 and apoB48 in the plasma, which are mainly carried by non-HDL particles [15, 25, 26]. Ezetimibe reduced the elevated plasma apoB100 and apoB48 levels by approximately 54 and $69 \%$, respectively (Fig. $2 \mathrm{~F}, P<$ 0.01). Although CM1 intervention had no effect on the plasma level of apo100, this molecule significantly reduced the plasma level of apoB48 by $27 \%$ (Fig. 2F, $P<$ 0.05). The alteration of plasma apoB48 was consistent with the plasma levels of TG. HFD also increased the plasma LPL level by $119 \%$ (Fig. 2G, $P<0.01$ ). Of note, ezetimibe intervention significantly increased the level of 
plasma LPL protein by nearly $38 \%(P<0.05)$. However, CM1 intervention did not affect the plasma level of LPL (Fig. 2G). In addition, HFD significantly increased plasma LPL activity (Fig. $2 \mathrm{H}, P<0.01$ ). In this study, neither ezetimibe nor CM1 intervention affected the plasma LPL activity (Fig. 2H).

\section{CM1 intervention modulated the liver genes}

SREBP-2 modulate the expression of several genes, such as PCSK9 and LDLR, which are involved in cholesterol metabolism at the transcriptional level [16, 18, 27]. HFD dramatically reduced the gene expression of SREBP-2 and PCSK9 by approximately 26 and 78\%, respectively (Fig. $3 \mathrm{~A}$ and $\mathrm{B}, P<0.01$ ). Ezetimibe increased the gene expression of SREBP-2 by $\sim 2.8$-fold (Fig. 3A, $P<0.01$ ) and PCSK9 by $\sim 3.8$-fold (Fig. $3 \mathrm{~B}, P<0.01$ ) in comparison with the HFD group. Of note, CM1 intervention reduced the mRNA levels of SREBP-2 and PCSK9 by approximately 88 and $80 \%$, respectively (Fig. 3A and B, $P<0.01)$. Furthermore, CM1 intervention also dramatically decreased the expression of these genes compared to the ezetimibe treatment (Fig. $3 \mathrm{~A}$ and $\mathrm{B}, P<0.01$ ). Therefore, CM1 may decrease cholesterol synthesis at the transcriptional level.

LXR $\alpha$ is an important modulator of cholesterol metabolism [28]. HFD did not affect the gene expression of
LXR $\alpha$ in this study (Fig. 3C). However, HFD dramatically increased the mRNA level of SREBP-1c by around 32-fold (Fig. 3D, $P<0.001$ ). Ezetimibe treatment notably decreased the gene expression of LXR $\alpha$ by $28 \%(P<$ 0.05 ) and SREBP-1c by $80 \%$ (Fig. $3 \mathrm{C}$ and $\mathrm{D}, P<0.01$ ). CM1 also reduced the gene expression of SREBP-1c by approximately 61\% (Fig. 3D, $P<0.05$ ), but not $\mathrm{LXR} \alpha$ (Fig. 3C). In this study, the $\mathrm{C} t$ numbers of LDLR, CYP7A1, and ABCG8 were greater than 30, suggesting the undetectable of these three genes.

\section{CM1 intervention improved the levels of CYP7A1 and ABCG5}

HFD notably increased the level of LDLR protein by 1.6fold and PCSK9 protein by 53\%, but not that of SR-BI and SREBP-2 (Fig. 4A-D). However, ezetimibe or CM1 administration had no effect on SR-B1 (Fig. 4A). Of note, ezetimibe decreased the protein expression of LDLR by $64 \%$ (Fig. 4B, $P<0.01$ ). Compared to ezetimibe, CM1 notably increased the amount of LDLR protein (Fig. 4B, $P<0.05$ ). As shown in Fig. 4D, CM1 dramatically decreased the expression of PCSK9 (38\%, $P<0.05)$, a protein that can promote LDLR degradation [16, 29]. The changes of LDLR protein in ezetimibe and CM1 intervention groups were consistent with the alteration of PCSK9. Additionally, the expression of SREBP-2 had

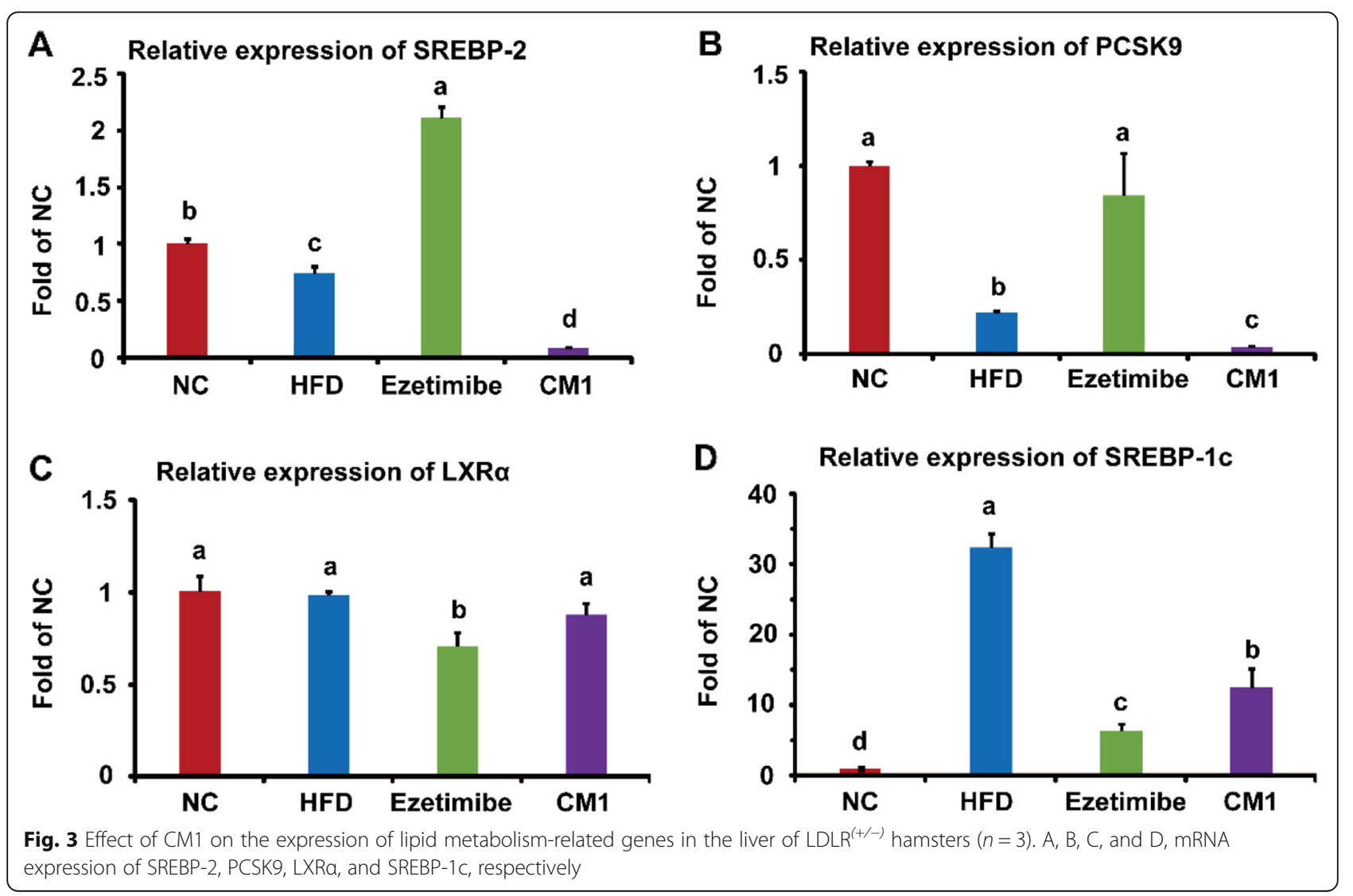


A \begin{tabular}{|r|c|c|l|c|}
\hline Group & NC & HFD & Ezeti. & CM1 \\
SR-BI \\
$\beta$-actin
\end{tabular}

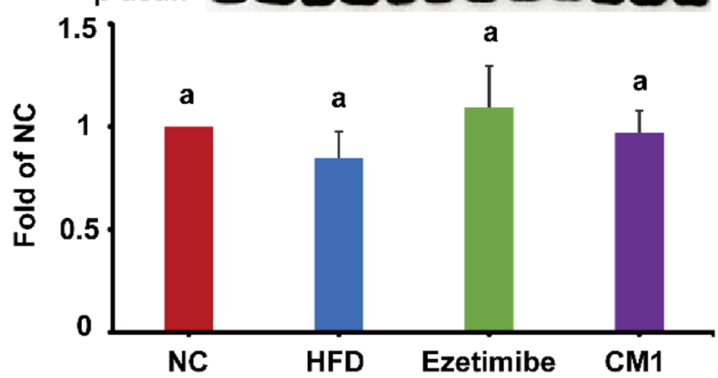

C

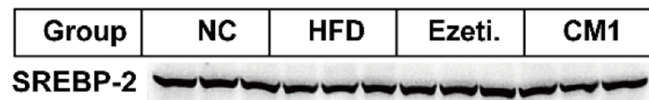

$\beta$-actin

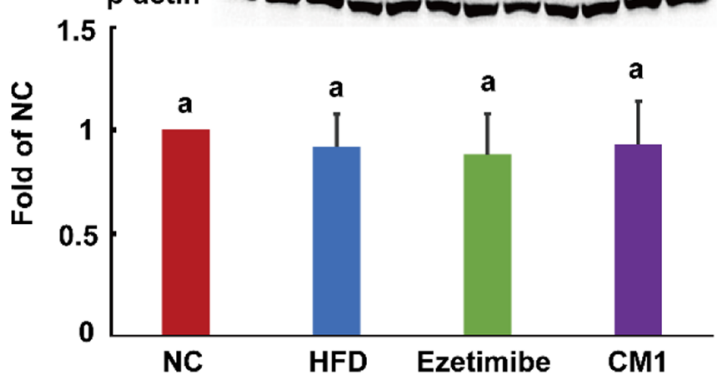

$\mathbf{E}$

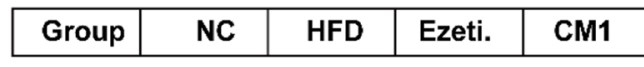

CYP7A1 $=m-m-m-m-m$ $\beta$-actin $\square-0-0-\infty-0-0$

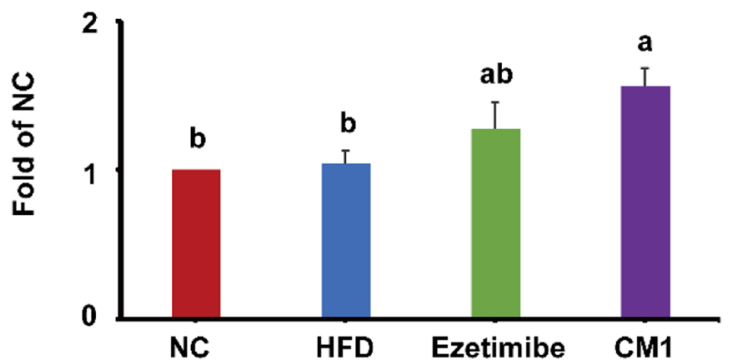

$\mathbf{G}$
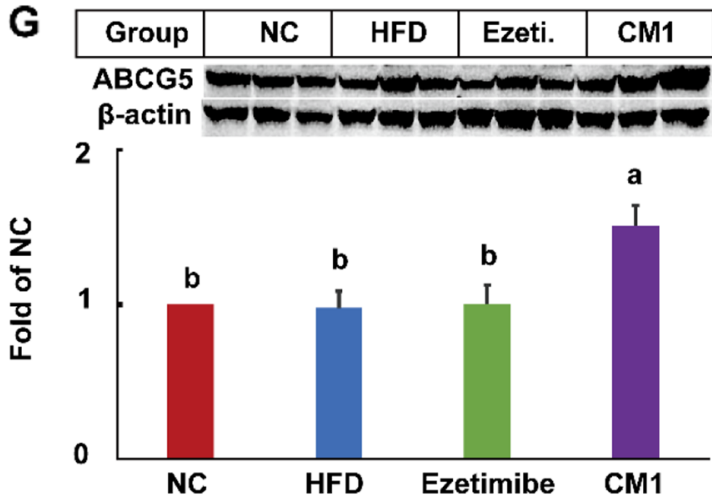

B
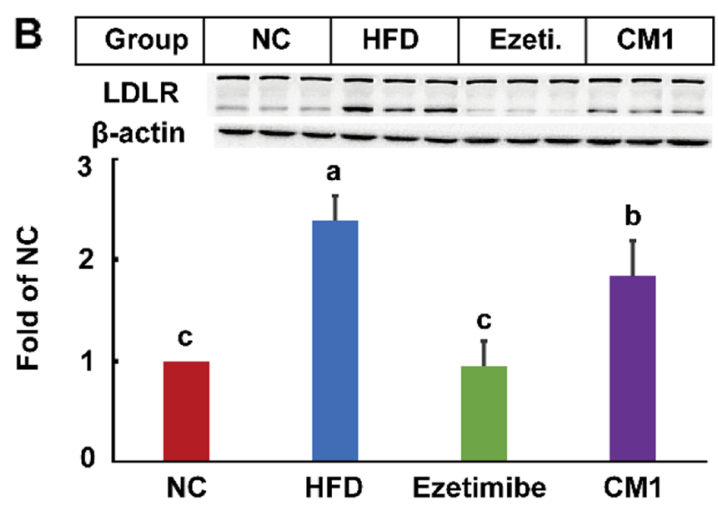

D
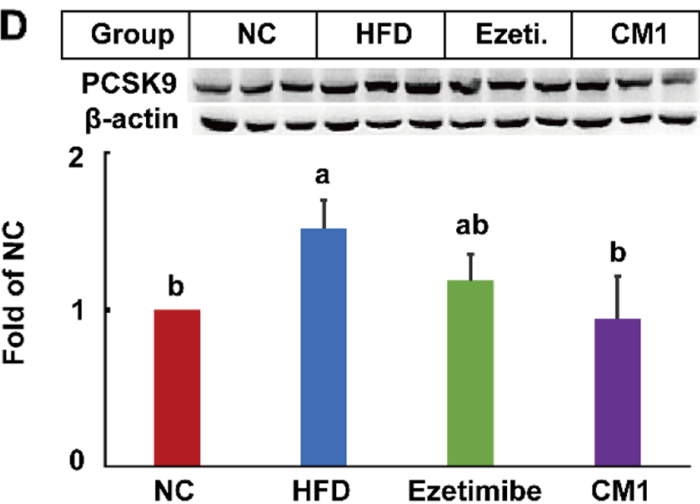

$\mathbf{F}$
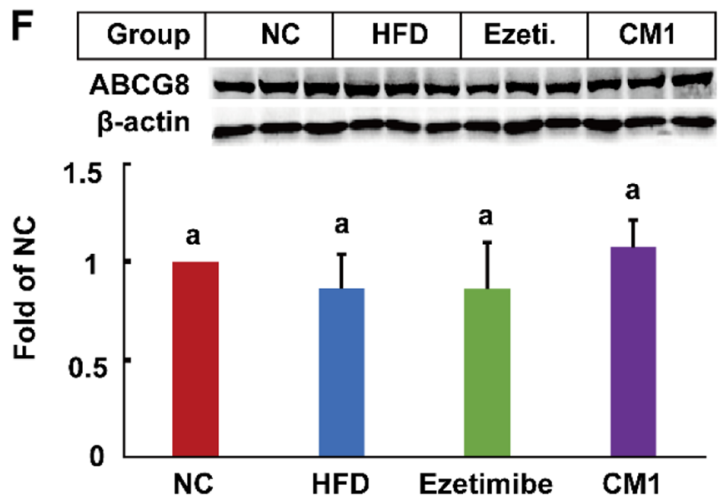

$\mathbf{H}$

\begin{tabular}{|c|c|c|c|c|}
\hline Group & NC & HFD & Ezeti. & CM1 \\
\hline LXR $\alpha$ \\
$\beta$-actin
\end{tabular}

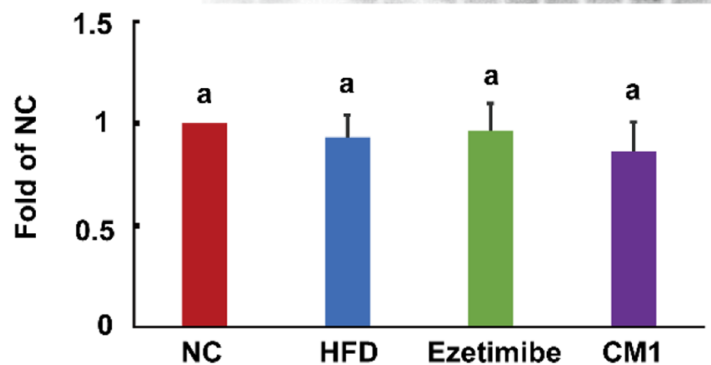

Fig. 4 Effect of $C M 1$ on the expression of TC metabolism-related proteins in the liver of the $L D L R^{(+/)}$hamsters $(n=5)$. A, SR-B1; B, LDLR; , SREBP-2; D, PCSK9; E, CYP7A1; F, ABCG8; G, ABCG5; H, LXRa expression and densitometric quantification 
no significant difference in ezetimibe or CM1 intervention group (Fig. 4C).

CYP7A1 is a key enzyme for bile acid synthesis [30]. CM1 treatment, but not ezetimibe, significantly enhanced the amount of CYP7A1 protein (Fig. 4E, $P<$ 0.05). A proportion of cholesterol metabolites in the liver are transported to the gall bladder for excretion $[28,31]$. In the present study, HFD and CM1 had no effect on the ABCG8 and LXR $\alpha$ proteins (Fig. 4F and H). However, CM1 treatment notably elevated the amount of hepatic ABCG5 protein in comparison with the HFD or ezetimibe treatment group (Fig. 4G, $P<0.05$ ). In the liver, CM1 intervention did not affect the level of NPC1L1 protein (Fig. 5A), which mediates the reabsorption of biliary cholesterol [31, 32].

\section{CM1 intervention modulated TG metabolism-related proteins in the liver of $\mathrm{LDLR}^{(+/-)}$hamsters}

HFD enhanced the level of PPAR $\alpha$ protein compared to the NC group (Fig. 5C, $P<0.05$ ). Ezetimibe had no effect on SREBP-1c and PPAR $\alpha$ proteins in comparison with the HFD group (Fig. 5B and C). However, ezetimibe decreased the expression of PPAR $\beta$ by approximately $40 \%$ (Fig. 5D, $P<0.05)$ and increased the levels of PPAR $\gamma$ and LPL protein by 35 and $43 \%$, respectively (Fig. $5 \mathrm{E}$ and F, $P<0.05)$. Of note, CM1 intervention enhanced the level of PPAR $\alpha$ protein by approximately $43 \%$ (Fig. $5 \mathrm{C}, P<$ 0.05 ), but not that of SREBP-1c, PPAR $\beta$, or PPAR $\gamma$ (Fig. $5 \mathrm{~B}, \mathrm{D}$ and $\mathrm{E})$. Furthermore, CM1 intervention notably enhanced the expression of PPAR $\beta$ protein in comparison with the ezetimibe intervention (Fig. 5D, $P<0.01$ ). Additionally, CM1 also increased the expression of LPL protein by $70 \%$ (Fig. 5 F, $P<0.01$ ) as that of ezetimibe.

\section{CM1 intervention inhibited the protein expression of NPC1L1 and SREBP-2 and enhanced the LXRa/ABCG8 in the gut}

In this study, HFD increased the mRNA expression of NPC1L1 by approximately 74\% (Fig. 6A, $P<0.05$ ). However, ezetimibe or CM1 intervention had no effect on the mRNA expression of NPC1L1. Furthermore, HFD notably reduced the mRNA expression of LXR $\alpha$ and ABCG 8 by 92 and 41.5\%, respectively (Fig. 6B and C). Ezetimibe reduced the mRNA level of ABCG8 by $73.8 \%$, but not $\mathrm{LXR} \alpha$, compared to the high-fat diet group (Fig. $6 \mathrm{C}$ ). On the contrary, CM1 intervention increased the mRNA expression of LXR $\alpha$ by 15.8 -fold and ABCG8 by 1.6-fold (Fig. 6B and C, $P<0.01$ ) compared to the HFD group. In contrast to ezetimibe, CM1 intervention also enhanced the mRNA expression of LXR $\alpha$ and ABCG8 $(P<0.01$, Fig. $6 \mathrm{~B}$ and $\mathrm{C})$. Additionally, SREBP-2 was undetectable in the small intestine due to the $\mathrm{C} t$ number was greater than 30 .
Compared to the NC group, HFD increased the expression of NPC1L1 protein by approximately 4.6-fold (Fig. 6D, $P<0.01$ ). Ezetimibe intervention showed no effect on the NPC1L1 protein in the present study. Mechanistically, ezetimibe prevents sterol-induced internalization of NPC1L1 [33, 34]. Of note, CM1 administration decreased the elevated NPC1L1 protein by around $39.5 \%$ (Fig. 6D, $P<0.05$ ). HFD also increased the level of ABCG8 protein $(P<0.01)$ and decreased the LXR $\alpha$ protein $(P<0.05)$ in the small intestine (Fig. $6 \mathrm{E}$ and F). Compared to the HFD group, CM1 intervention dramatically increased the level of ABCG8 protein (Fig. $6 \mathrm{~F}, P<0.05)$, but not LXR $\alpha$, in the small intestine. Furthermore, HFD intervention increased the level of SREBP-2 protein by $48 \%(P<0.05)$ compared to the NC group (Fig. 6G). Ezetimibe significantly decreased the elevated SREBP-2 by $42 \%$ (Fig. 6G, $P<0.05$ ). Similarly, CM1 intervention reduced the expression of SREBP-2 by 64\% (Fig. 6G, $P<0.01$ ) when compared with the HFD group. The inhibitory effect of CM1 on SREBP-2 was greater than that of ezetimibe (38\% reduction, Fig. 6G, $P<0.05)$.

\section{CM1 modulated the lipid metabolism in the Epididymal}

fat

In this study, HFD increased the fat pad index of the $\mathrm{LDLR}^{(+/-)}$hamsters by approximately 74\% (Fig. 7A, $P<$ 0.01). CM1 administration, but not ezetimibe, significantly decreased the elevated fat pad index by around $39 \%(P<0.05)$. HFD also increased the diameter of the adipocyte by $28.3 \%(P<0.01)$, whereas $C M 1$ treatment decreased the elevated diameter of the adipocyte by $34.9 \%$ (Fig. $7 \mathrm{~B}$ and $\mathrm{C}, P<0.01$ ). Moreover, HFD increased the expression of PPAR $\alpha$ and SREBP-1c proteins by approximately 48 and $38 \%$, respectively, in the epididymal fat (Fig. 7D and F, $P<0.05$ ). Of note, ezetimibe administration significantly decreased the expression of SREBP-1c (Fig. 7F) by 37\%, and enhanced the expression of PPAR $\alpha$ by $58 \%$ and PPAR $\gamma$ by $75 \%$ (Fig. 7D and E). Similarly, CM1 intervention reduced the expression of SREBP-1c by $49 \%(P<0.05)$ and increased the level of PPAR $\alpha$ by $46 \%(P<0.05)$ when compared with the HFD group. Furthermore, CM1 intervention decreased the level of PPAR $\gamma$ protein by approximately 67\% (Fig. 7E, $P<0.01)$. In the adipose tissue, ATGL promotes the hydrolysis of TGs and the production of fatty acids, thereby playing an important role in energy homeostasis [35]. As shown in Fig. 7G, HFD significantly decreased ATGL protein by approximately $38 \%(P<0.01)$ compared to the regular chow diet. Ezetimibe or CM1 intervention enhanced the level of ATGL protein by 50 and $65 \%$, respectively, compared to the HFD group (Fig. 7G, $P<0.05)$. 

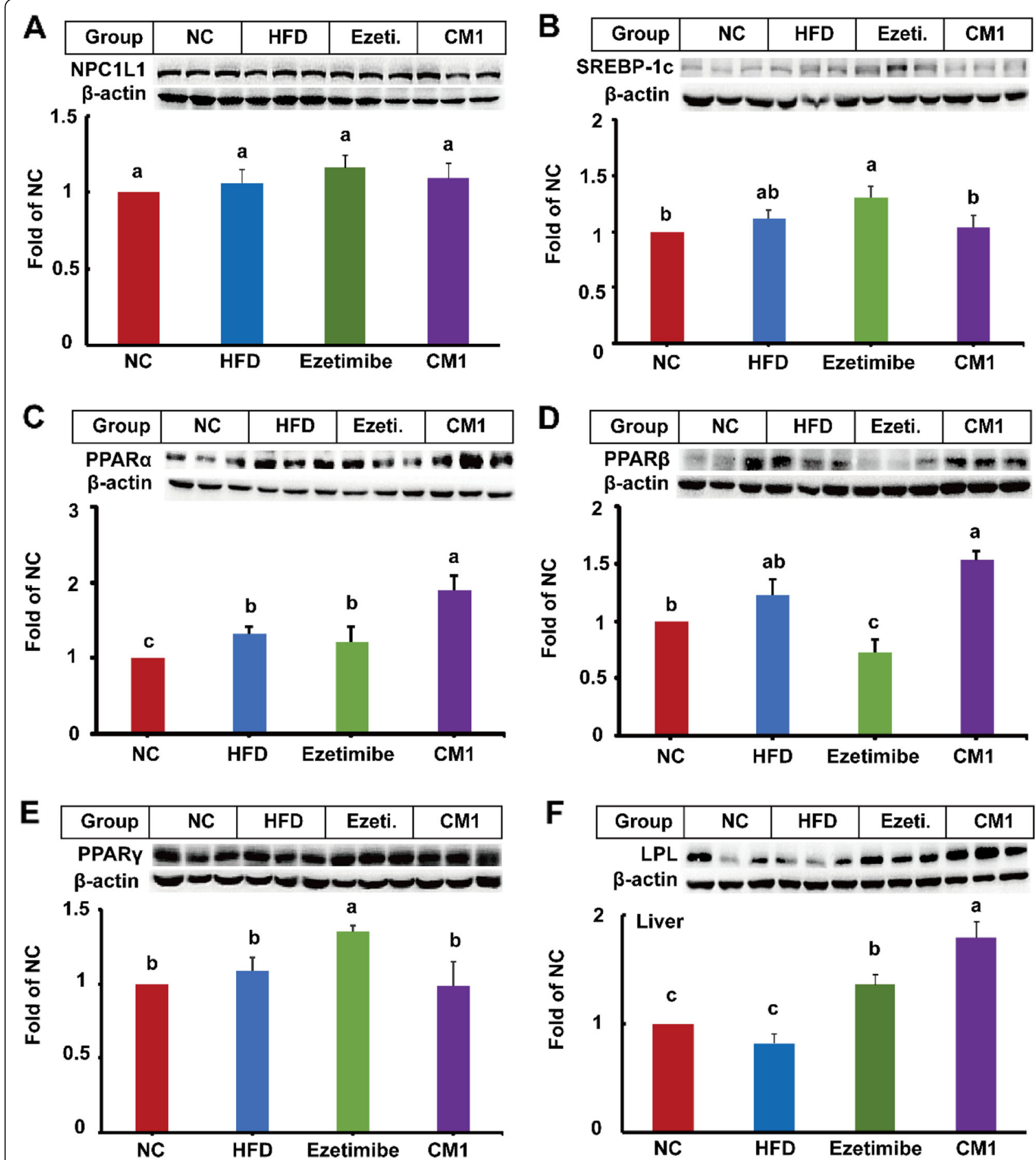

Fig. 5 Effect of CM1 on the expression of NPC1L1 and TG metabolism-related proteins in the liver of the $\operatorname{LDLR}^{(+/-)}$hamsters $(n=5)$. A, NPC1L1; B, SREBP-1C; C, PPARa; D, PPARB; E, PPARY; F, LPL expression and densitometric quantification

CM1 decreased the lipid droplet formation in vitro As shown in Fig. 8A, insulin successfully induced the formation of lipid droplet in 3T3-L1 cells, whereas CM1 intervention obviously decreased the lipid droplet formation. In this study, lipid droplet formation was not observed in the blank group. Therefore, the effect of CM1 intervention was only compared to the differentiated group. Statistically, CM1 intervention decreased the average number lipid droplets by $54.2 \%$ $(P<0.01)$. It also reduced the average diameter of lipid droplets by $29.7 \%$ (Fig. $8 \mathrm{C}, P<0.01$ ). In the differentiated group, the mRNA expression of PPAR $\gamma$ 

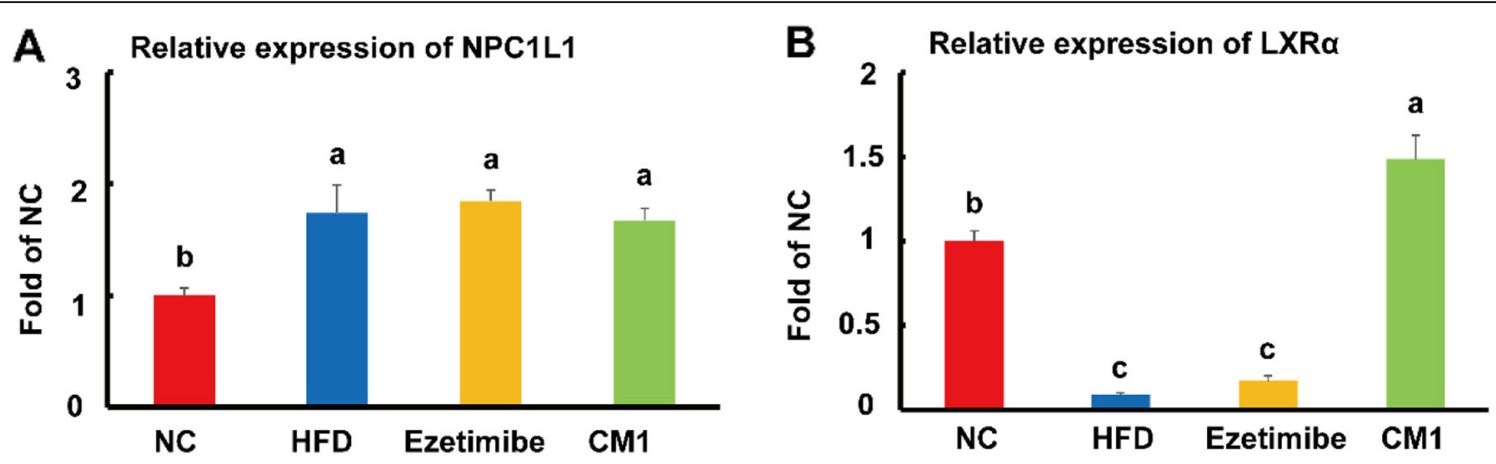

C Relative expression of $A B C G 8$

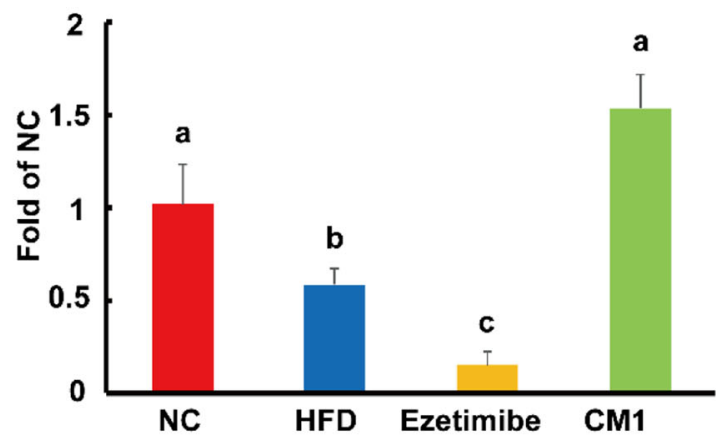

D

\begin{tabular}{|c|c|c|l|c|}
\hline Group & NC & HFD & Ezeti. & CM1 \\
\hline NPC1L1 & - \\
$\beta$-actin & $-\infty-\infty$
\end{tabular}

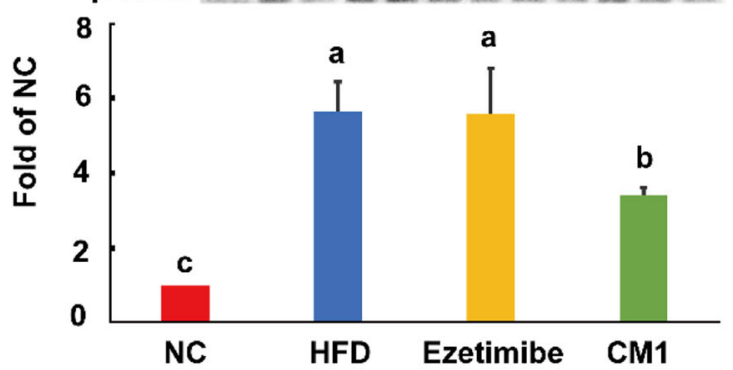

E
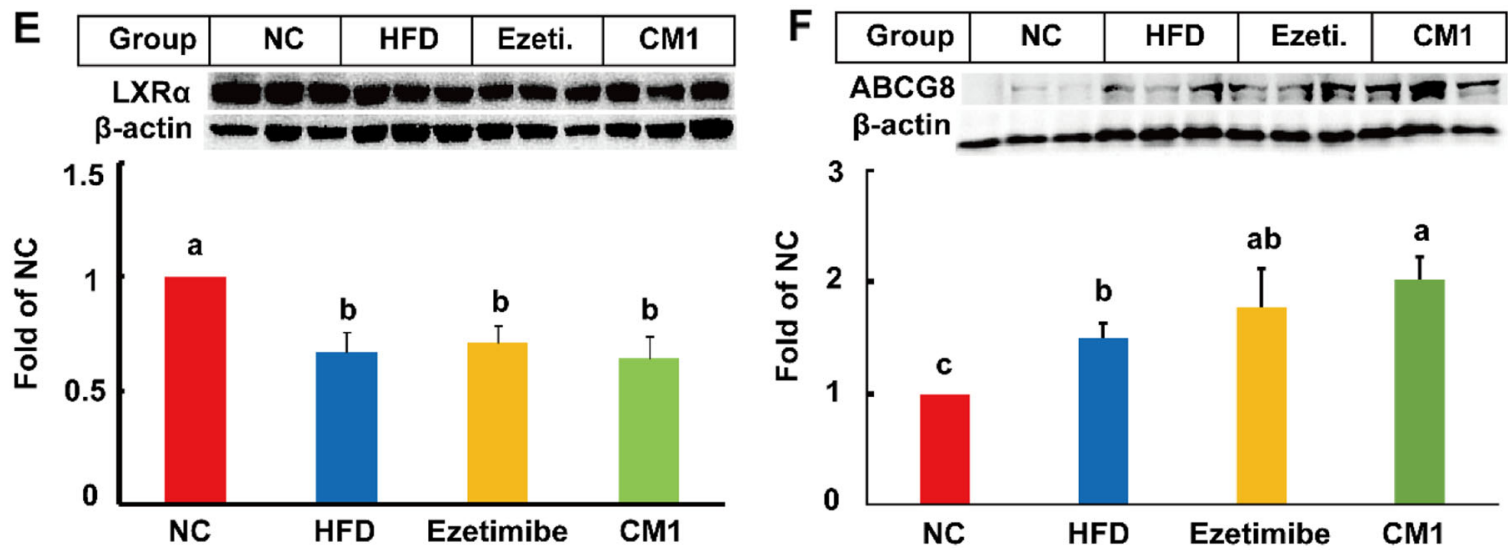

$\mathbf{G}$
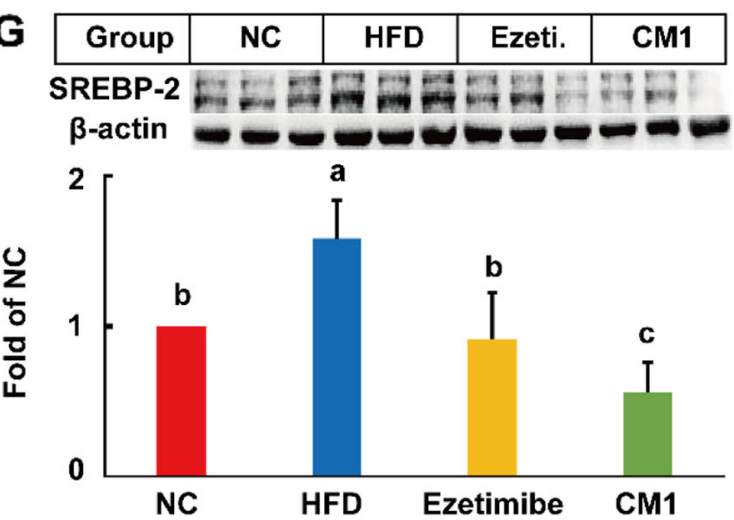

Fig. 6 Effect of $C M 1$ on the expression of lipid metabolism-related genes and proteins in the small intestine of the $\operatorname{LDLR}^{(+/-)}$hamsters $(n=5$ or 3). $A$, relative mRNA expression of $N P C 1 L 1 ; B$, relative mRNA expression of $L X R a ; C$, relative mRNA expression of $A B C G 8 ; D, N P C 1 L 1 ; E$, $L X R a ; F$, $A B C G 8 ; G$, SREBP-2 expression and densitometric quantification in the small intestine 


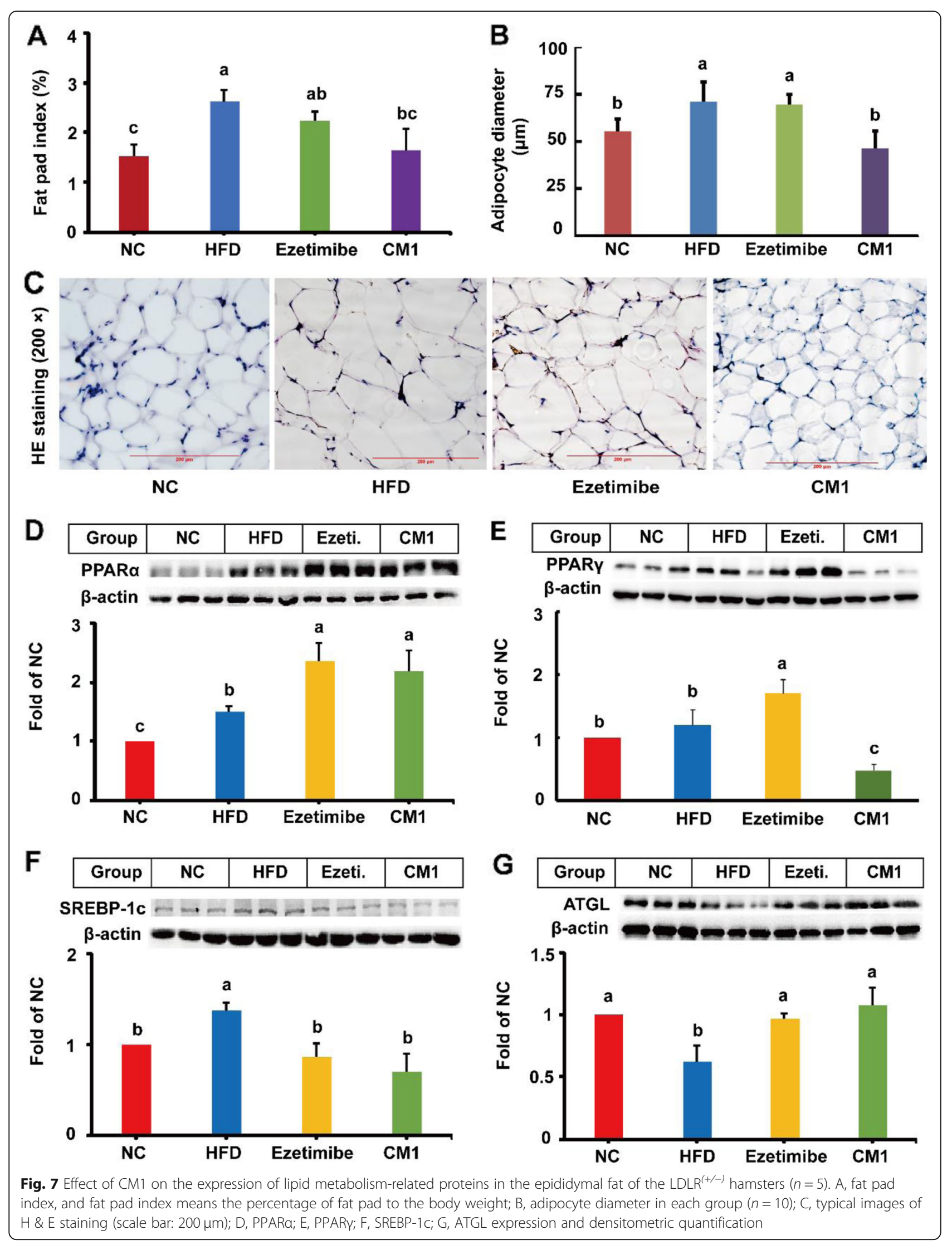




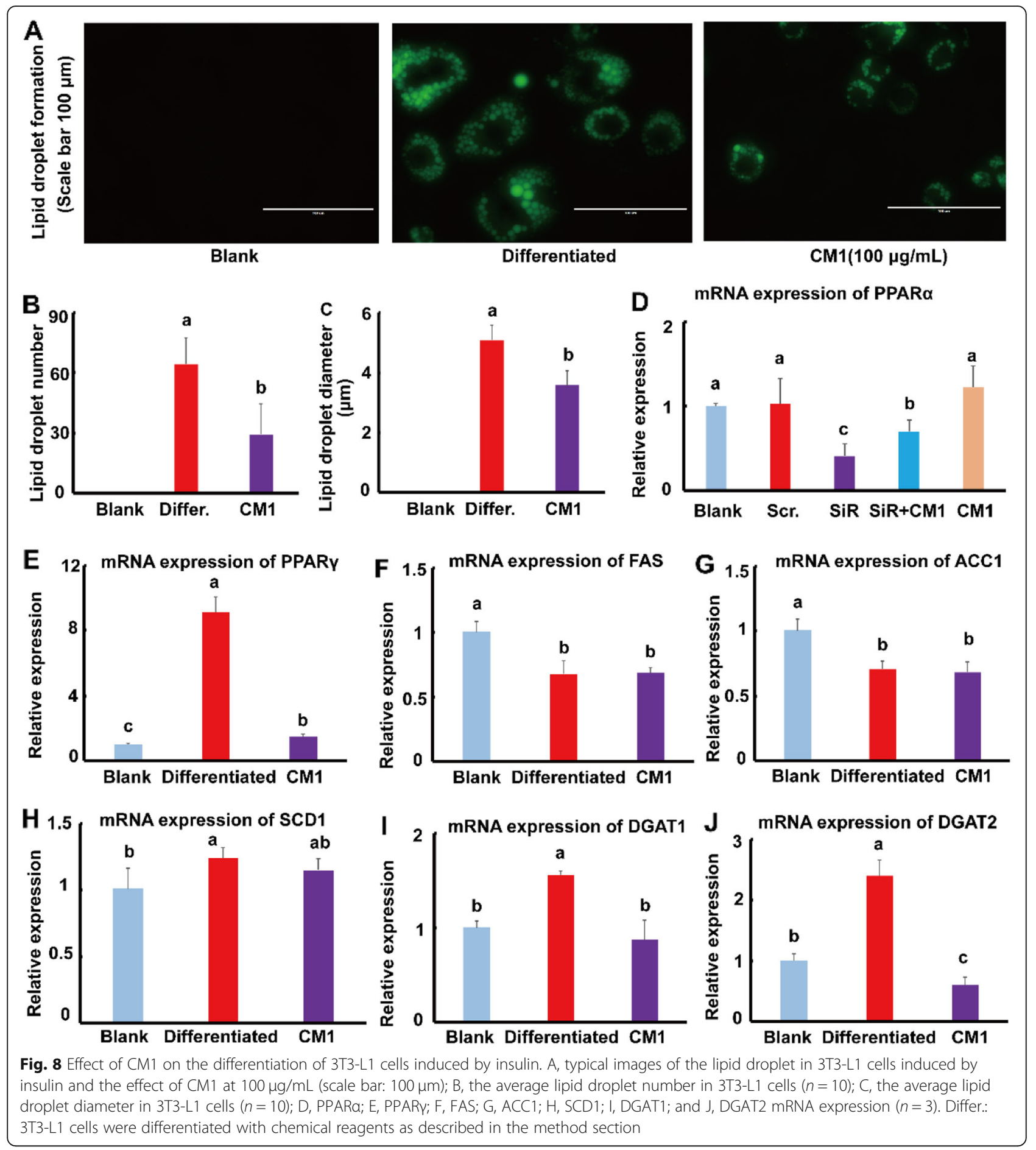

increased by 13.7 -fold (Fig. $8 \mathrm{E}, P<0.01$ ). Furthermore, the levels of stearoyl-CoA desaturase 1 (SCD1), diacylglycerol acyltransferase (DGAT) 1 and 2 enhanced 1.4-fold $(P<0.01)$, 55.8\% $(P<0.05)$, and 1.4 -fold $(P<0.01)$, respectively, compared with the blank group (Fig. $8 \mathrm{H}, \mathrm{I}$, and J). PPAR $\alpha$ siRNA dramatically reduced the mRNA expression of PPAR $\alpha$ by approximately $59 \%$ compared to the scrambled siRNA group $(P<0.05)$, while CM1 intervention increased the mRNA expression of PPAR $\alpha$ by approximately $72 \%$ compared to the single PPAR $\alpha$ siRNA treatment group $(P<0.05$, Fig. 8D). The gene expression of fatty acid synthase (FAS) and acetyl-CoA carboxylase 1 (ACC1) decreased by approximately $29 \%$ in the differentiated group compared to the blank group (Fig. 8 F and $G, P<0.05$ ). The above results further demonstrated that PPAR $\gamma$ is important for adipocyte differentiation. It is worth noted that 
CM1 intervention decreased the mRNA expression of PPAR $\gamma$, DGAT1, and DGAT2 by $83.8 \%$ (Fig. $8 \mathrm{E}, P<0.01$ ), $43.8 \%$ (Fig. 8I, $P<0.05$ ), and $74.7 \%$ (Fig. 8J, $P<0.01$ ), respectively. Furthermore, CM1 intervention did not affect the mRNA expression of PPAR $\alpha$, SCD1, FAS, and $\mathrm{ACC} 1$ when compared with the differentiated group.

\section{Discussion}

The water extracts or polysaccharides of the Cordyces species have anti-hyperlipidemic effects in mice [10-13]. However, the lipid profile in mice is distinct from humans [25]. In this study, the polysaccharide CM1 from $C$. militaris displayed powerful hypolipidemic effects in LDLR $^{(+-)}$hamsters, which have a human-like lipid profile $[4,15,24]$. When compared with ezetimibe treatment, CM1 showed distinct effects on many genes and proteins. Therefore, CM1 exerts hyperlipidemic effects by distinct mechanisms compared to ezetimibe as a result of structural differences (Fig. 1A).

Firstly, CM1 may reduce plasma TC by enhancing reverse cholesterol transport. SR-BI and LDLR mediate cholesterol transport from lipoproteins to the liver, contributing to a reduction of plasma TC $[16,27,36]$. A recent study suggested that $\mathrm{CM} 1$ can enhance the expression of SR-B1 protein in apoE ${ }^{(-/-)}$mice [37]. However, CM1 had no effect on SR-BI protein in this study, and it reduced the plasma level of apoAI, an important acceptor of peripheral cholesterol [17, 38], as that of ezetimibe. Although the plasma apoAI level was similar, CM1 intervention seemed to enhance the level of HDL cholesterol compared to ezetimibe, suggesting CM1 may improve the transfer of plasma cholesterol from HDL particles to the liver. A previous study already demonstrated that CM1 may improve HDL-mediated cholesterol efflux [17]. Recent studies also indicated that water-soluble components of Cordyceps species can lower hyperlipidemia [10-13, 39]. This study suggested that CM1 is one of the water-soluble components with hypolipidemic effects.

The potential LDLR promoting effect of CM1 was consistent with the finding in $\mathrm{apoE}^{(-/-)}$mice [37]. Of note, the reductions of PCSK9 at the gene and protein levels in CM1 group were consistent with the decrease of SREBP-2 at the transcription level. However, a recent study demonstrated that the polysaccharide CM3-SII can enhance the SREBP-2 pathway in Huh7 cells [19]. These differences may be caused by either the distinct structure of the polysaccharides or the experimental models. In this study, although ezetimibe enhanced the gene expression of SREBP-2 and PCSK9, it significantly reduced the level of LDLR protein. These data suggested that ezetimibe may modulate these proteins at a posttranscriptional level. Additionally, the inconsistency of the effect of ezetimibe on the SREBP-2 pathway between this study and previous studies may be attributed to the short intervention time (only 3 or 7 days) and the regular chow diet rather than the high-fat diet used in the previous studies [40-42].

Furthermore, CM1 intervention increased the protein expression of CYP7A1, which suggested that CM1 could improve the synthesis of bile acid. As found in the previous study [37], CM1 intervention may increase lipid excretion via enhancing the protein expression of ABCG5/ 8. Furthermore, the C. militaris polysaccharide CM3II could also enhance the LXR $\alpha / A B C G 8$ pathway in apoE $\mathrm{E}^{(-/-)}$mice [10]. Unlike the effect of ezetimibe, CM1 can directly inhibit the protein level of NPC1L1. Therefore, the polysaccharide CM1 may inhibit NPC1L1mediated cholesterol absorption from small intestine by a distinct mechanism compared to ezetimibe. These data suggested that the TC-lowering effect of CM1 may be, at least in part, attributed to the reduction of NPC1L1mediated cholesterol absorption, SR-B1-mediated cholesterol uptake, CYP7A1-mediated cholesterol conversion, and the subsequent ABCG5/8-mediated lipid excretion.

Secondly, CM1 may reduce plasma TG concentration by inhibiting TG synthesis and promoting fatty acid degradation. Similar as that of ezetimibe, CM1 may reduce TG synthesis by inhibiting the transcription of SREBP1c. Accumulating evidence have demonstrated that SREBP-1c can regulate the expression of lipogenic genes at the transcriptional level, thereby modulating TG metabolism [18, 27]. Unlike ezetimibe, CM1 had no effect on the plasma level of apoB100. However, CM1 reduced the plasma level of apoB48 as that of ezetimibe, suggesting this molecule may act on the apoB48 editing in the small intestine rather than apoB100 editing in the liver. The effect of ezetimibe on apoB and VLDL particles were consistent with previous studies [43-45]. Mechanistically, ezetimibe can inhibit apoB secretion and reduce the production and export of chylomicron and VLDL particles $[43,44,46]$. A reduction of TG level in the plasma VLDL fractions of CM1-treated hamsters was observed compared to the HFD group. This reduction can be partially attributed to the reduced apoB48 level but no the plasma LPL, a key enzyme in hydrolysis of lipoprotein and chylomicron [47, 48]. Furthermore, PPARs are activated by a large variety of fatty acids and their derivatives. PPAR $\alpha$ and PPAR $\beta$ are major inducers of fatty acid oxidation in liver, whereas PPAR $\gamma$ is a major activator of adipocyte differentiation [37, 49]. This study suggested that CM1 can lower TG by upregulating PPAR $\alpha$-mediated $\beta$-oxidation and LPL-mediated lipoprotein degradation in the liver. A recent integrated bioinformatics analysis demonstrated that CM1 can regulate the PPAR signaling in apo $\mathrm{E}^{(-/-)}$mice [37]. From the perspective of structure-activity relationship, the 
modulatory effects of CM1 on PPAR $\alpha$ and SREBPs may be attributed to the $\beta$-D-linked glycosyls contained in CM1 $[10,50]$. It has previously been shown that Ganoderma lucidum polysaccharides containing $\beta$-D-glucans can inhibit fatty acid synthesis by inhibiting SREBP-1c [51, 52].

Thirdly, CM1 may inhibit adipocyte differentiation in $\mathrm{LDLR}^{(+-)}$hamsters. A previous study demonstrated that the fermented C. militaris extract can inhibit adipocyte hypertrophy in mice [13]. As PPAR $\gamma$ is a major activator of adipocyte differentiation [49], the inhibitory effect of CM1 on the adipose of the $\mathrm{LDLR}^{(+/)}$hamster can be partially attributed to its downregulation of PPARy. Other natural polysaccharides, such as fucoidan, also have the ability of inhibiting PPARY [53]. Furthermore, the enhanced protein expression of PPAR $\alpha$ in the adipose may increase the degradation of fatty acids, contributing to the reduced fat pad index. Additionally, the reduction of adipose in the CM1 treatment group may also be attributed to the enhanced expression of ATGL, which can promote the hydrolysis of TGs and the production of fatty acids [35]. In line with the results seen in the adipose, the bioactive polysaccharide CM1 can inhibit the differentiation of 3T3-L1 cells by downregulation of PPARy. Furthermore, CM1 may inhibit TG synthesis via reducing DGAT1 and DGAT2 [54], thereby inhibiting adipocyte differentiation.

\section{Strengths and limitations}

As concluded in Fig. 9, this bioactive polysaccharide CM1 can alleviate hyperlipidemia and adipocyte differentiation in $\mathrm{LDLR}^{(+/)}$hamsters by several proposed mechanisms. Firstly, it increases the levels of CYP7A1 and $\mathrm{ABCG} 5 / 8$, that may contribute to the potential conversion and excretion of cholesterol, respectively. Secondly, CM1 decreases the protein expression of NPC1L1 and SREBP-2 in the gut, which may lead to a potential reduction of cholesterol absorption and synthesis. Thirdly, it may lower TG via enhancing the levels of LPL and PPAR $\alpha$ in the liver and decreasing the apoB48 production in the small intestine. Finally, CM1 intervention leads to a reduction of adipocyte differentiation potentially by modulating multiple molecules in the epididymal fat.

The limitations of this study are listed below. (1), as CM1 reduced the expression of NPC1L1 protein, whether this polysaccharide can inhibit intestinal cholesterol absorption is an interesting question and should be answered in future studies. (2), genes exert their functions after being translated to the corresponding

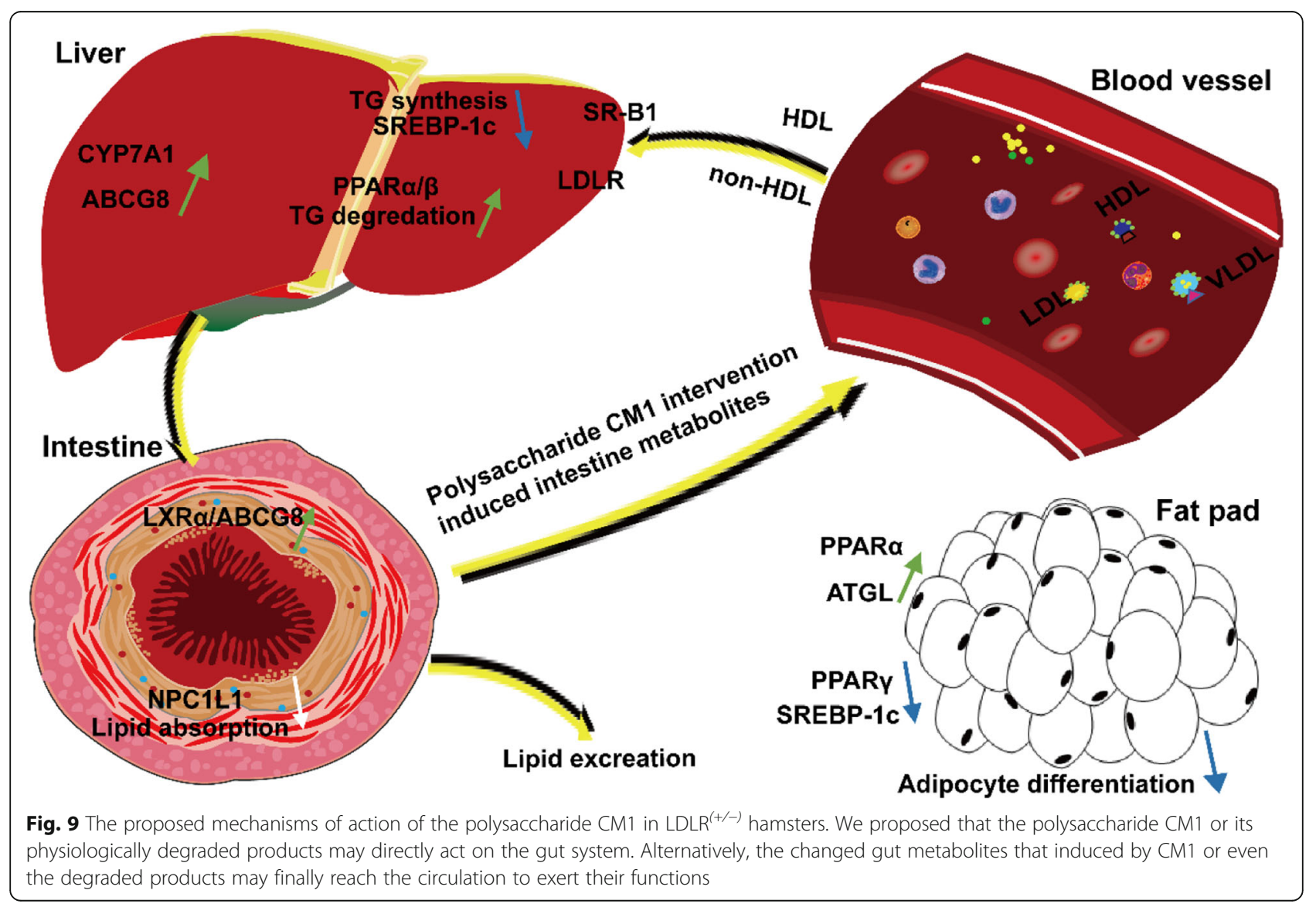


proteins, and many factors may influence the translational process, contributing to the inconsistent of the gene and protein expression. As a limitation of this study, whether CM1 affects the above process need to be clarified in the future. (3), as a primary study, only some genes related to adipocyte differentiation were examined in vitro. Whether CM1 can influence the expression of proteins that associated with adipocyte differentiation need to be investigated by comparation with a suitable positive control, such as PPARy agonist, which has been demonstrated to act on adipocyte differentiation. Importantly, polysaccharide may be degraded in vivo by gastric acid and/or gut microbiota, it is impelled to investigate the effect and especially the mechanisms of CM1 in vitro using its physiologically degraded products. (4), given the big molecular weight of the polysaccharide CM1, its action both in vitro and in vivo is an interesting topic to be studied in the future. One possible mechanism by which CM1 or its physiologically degraded products modulate these genes or proteins in different organs might be by affecting gut microbiota and the metabolites, that have been demonstrated to be associated with cardiovascular diseases $[55,56]$. Future research is needed to clarify what effect CM1 has on gut microbiota, and how other potential effects contribute to CM1-mediated lipid homeostasis.

\section{Conclusions}

This long-term study demonstrated for the first time that the polysaccharide CM1 from the fruiting body of C. militaris has an attractive effect on lowering hyperlipidemia in $\mathrm{LDLR}^{(+/-)}$hamsters via influencing on multiple pathways. These findings provide evidence that the polysaccharide CM1 can be used for treatment of the patients with abnormal lipid profiles as monotherapy or in combination with other lipid-lowering compounds. Alternatively, CM1 can be supplemented as a food additive for daily care of the patients with hyperlipidemia. Therefore, this study highlights the potential applications of polysaccharides from C. militaris in both food and pharmaceutical areas.

\section{Abbreviations}

ABC: ATP binding cassette; ACC1: Acetyl-CoA carboxylase 1; Apo: Apolipoprotein; ATGL: Adipose triglyceride lipase; CETP: Cholesteryl ester transfer protein; CVD: Cardiovascular disease; CYP7A1: Cholesterol 7-ahydroxylase A1; DGAT: Diacylglycerol acyltransferase; FAS: Fatty acid synthase; HDL: High-density lipoprotein; LDLR: Low-density lipoprotein receptor; $\operatorname{LDLR}^{(-)-1}$ : Low-density lipoprotein receptor (LDLR)-deficient;

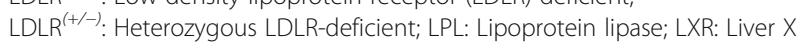
receptor; NPC1L1: Niemann-Pick C1-like 1; PPAR: Peroxisome proliferatoractivated receptor; PCSK9: Proprotein convertase subtilisin/kexin type 9; RTqPCR: Real-time quantitative PCR; SCD1: Stearoyl-CoA desaturase 1; SRB1: Scavenger receptor B type 1; SREBP: Sterol regulatory element-binding protein; TC: Total cholesterol; TG: Triglyceride; VLDL: Very low-density lipoprotein

\section{Supplementary Information}

The online version contains supplementary material available at https://doi. org/10.1186/s12944-021-01606-6.

\section{Additional file 1.}

\section{Acknowledgements}

Not applicable.

\section{Authors' contributions}

Wen-Qian Yu, Fan Yin and Ping Lin: Formal analysis and Data Curation; Bin Xia, Yan-Jie Li and Nuo Shen: Resources and Investigation; Shou-Dong Guo: Funding acquisition, writing and editing. All authors have read and agree to the published version of the manuscript.

\section{Funding}

This work was supported by the National Natural Science Foundation of China (81770463 and 82070469).

\section{Availability of data and materials}

The datasets used and/or analyzed during the current study are available from the corresponding author on reasonable request.

\section{Declarations}

\section{Ethics approval}

This animal study was approved by the laboratory animal ethics committee of Weifang Medical University (2020SDL106-3).

\section{Consent for publication}

All authors agree to publish this article in the journal of Lipids in Health and Disease.

\section{Competing interests}

The authors declare that they have no competing interests.

Received: 27 September 2021 Accepted: 26 November 2021

Published online: 13 December 2021

\section{References}

1. Zhao D, Liu J, Wang M, Zhang X, Zhou M. Epidemiology of cardiovascular disease in China: current features and implications. Nat Rev Cardiol. 2019; 16(4):203-12. https://doi.org/10.1038/s41569-018-0119-4.

2. Leong DP, Joseph PG, McKee M, Anand SS, Teo KK, Schwalm JD, et al. Reducing the global burden of cardiovascular disease, part 2: prevention and treatment of cardiovascular disease. Circ Res. 2017;121(6):695-710. https://doi.org/10.1161/CIRCRESAHA.117.311849.

3. Soppert J, Lehrke M, Marx N, Jankowski J, Noels H. Lipoproteins and lipids in cardiovascular disease: from mechanistic insights to therapeutic targeting. Adv Drug Deliv Rev. 2020;159:4-33. https://doi.org/10.1016/j.addr.2020.07.01 9.

4. Xia B, Lin P, Ji Y, Yin J, Wang J, Yang $X$, et al. Ezetimibe promotes CYP7A1 and modulates PPARs as a compensatory mechanism in LDL receptordeficient hamsters. Lipids Health Dis. 2020;19(1):24. https://doi.org/10.1186/ s12944-020-1202-5.

5. Wang DQ. Regulation of intestinal cholesterol absorption. Annu Rev Physiol. 2007;69(1):221-48. https://doi.org/10.1146/annurev.physiol.69.031905.160725.

6. Garcia-Calvo M, Lisnock J, Bull HG, Hawes BE, Burnett DA, Braun MP, et al. The target of ezetimibe is Niemann-pick C1-like 1 (NPC1L1). Proc Natl Acad Sci U S A. 2005;102(23):8132-7. https://doi.org/10.1073/pnas.0500269102.

7. Panda AK, Swain KC. Traditional uses and medicinal potential of Cordyceps sinensis of Sikkim. J Ayurveda Integr Med. 2011;2(1):9-13. https://doi.org/1 0.4103/0975-9476.78183.

8. Zhang J, Wen C, Duan Y, Zhang H, Ma H. Advance in Cordyceps militaris (Linn) link polysaccharides: isolation, structure, and bioactivities: a review. Int J Biol Macromol. 2019;132:906-14. https://doi.org/10.1016/j.ijbiomac.2019.04. 020.

9. Cui JD. Biotechnological production and applications of Cordyceps militaris, a valued traditional Chinese medicine. Crit Rev Biotechnol. 2015:35(4):47584. https://doi.org/10.3109/07388551.2014.900604. 
10. Yang $X$, Lin P, Wang J, Liu N, Yin F, Shen N, et al. Purification, characterization and anti-atherosclerotic effects of the polysaccharides from the fruiting body of Cordyceps militaris. Int J Biol Macromol. 2021;181:890904. https://doi.org/10.1016/j.jijbiomac.2021.04.083.

11. Koh JH, Kim JM, Chang UJ, Suh HJ. Hypocholesterolemic effect of hot-water extract from mycelia of Cordyceps sinensis. Biol Pharm Bull. 2003;26(1):84-7. https://doi.org/10.1248/bpb.26.84.

12. Kim SB, Ahn B, Kim M, Ji HJ, Shin SK, Hong IP, et al. Effect of Cordyces militaris extract and active constituents on metabolic parameters of obesity induced by high-fat diet in C58BL/6J mice. J Ethnopharmacol. 2014;151(1): 478-84. https://doi.org/10.1016/j.jep.2013.10.064.

13. Tran NKS, Kim GT, Park SH, Lee D, Shim SM, Park TS. Fermented Cordyceps militaris extract prevents hepatosteatosis and adipocyte hypertrophy in high fat diet-fed mice. Nutrients. 2019;11(5):1015. https://doi.org/10.3390/nu11051 015.

14. Paterson RR. Cordyceps: a traditional Chinese medicine and another fungal therapeutic biofactory? Phytochemistry. 2008;69(7):1469-95. https://doi.org/1 0.1016/j.phytochem.2008.01.027.

15. Guo X, Gao M, Wang Y, Lin X, Yang L, Cong N, et al. LDL receptor geneablated hamsters: a rodent model of familial hypercholesterolemia with dominant inheritance and diet-induced coronary atherosclerosis. EBioMedicine. 2018;27:214-24. https://doi.org/10.1016/j.ebiom.2017.12.013.

16. Guo S, Xia XD, Gu HM, Zhang DW. Proprotein convertase subtilisin/Kexintype 9 and lipid metabolism. Adv Exp Med Biol. 2020;1276:137-56. https:// doi.org/10.1007/978-981-15-6082-8_9.

17. Hu S, Wang J, Li F, Hou P, Yin J, Yang Z, et al. Structural characterisation and cholesterol efflux improving capacity of the novel polysaccharides from Cordyceps militaris. Int J Biol Macromol. 2019;131:264-72. https://doi.org/10.1 016/j.ijbiomac.2019.03.078.

18. Li T, Hu SM, Pang XY, Wang JF, Yin JY, Li FH, et al. The marine-derived furanone reduces intracellular lipid accumulation in vitro by targeting LXRa and PPARa. J Cell Mol Med. 2020;24(6):3384-98. https://doi.org/10.1111/ jcmm.15012.

19. Wang J, Wang Y, Yang $X$, Lin $P$, Liu N, Li X, et al. Purification, structural characterization, and PCSK9 secretion inhibitory effect of the novel alkaliextracted polysaccharide from Cordyceps militaris. Int J Biol Macromol. 2021; 179:407-17. https://doi.org/10.1016/j.ijbiomac.2021.02.191.

20. Adomshick V, Pu Y, Veiga-Lopez A. Automated lipid droplet quantification system for phenotypic analysis of adipocytes using CellProfiler. Toxicol Mech Methods. 2020;30(5):378-87.

21. Guo SD, Cui YJ, Wang RZ, Wang RY, Wu WX, Ma T. Separation, purification and primary reverse cholesterol transport study of Cordyceps militaris polysaccharide. China J Chin Mater Med. 2014;39(17):3316-20.

22. Yin J, Wang J, Li F, Yang Z, Yang $X$, Sun W, et al. The fucoidan from the brown seaweed Ascophyllum nodosum ameliorates atherosclerosis in apolipoprotein E-deficient mice. Food Funct. 2019;10(8):5124-39. https://doi. org/10.1039/C9FO00619B.

23. Zhang JY, Zhang F, Hong CQ, Giuliano AE, Cui XJ, Zhou GJ, et al. Critical protein GAPDH and its regulatory mechanisms in cancer cells. Cancer Biol Med. 2015;12(1):10-22. https://doi.org/10.7497/j.issn.2095-3941.2014.0019.

24. Wu Y, Xu MJ, Cao Z, Yang C, Wang J, Wang B, et al. Heterozygous Ldlrdeficient hamster as a model to evaluate the efficacy of PCSK9 antibody in hyperlipidemia and atherosclerosis. Int J Mol Sci. 2019;20(23):5936. https:// doi.org/10.3390/ijms20235936.

25. Gao S, He L, Ding Y, Liu G. Mechanisms underlying different responses of plasma triglyceride to high-fat diets in hamsters and mice: roles of hepatic MTP and triglyceride secretion. Biochem Biophy Res Commun. 2010;398(4): 619-26. https://doi.org/10.1016/j.bbrc.2010.05.114.

26. Reaves SK, Wu JY, Wu Y, Fanzo JC, Wang YR, Lei PP, et al. Regulation of intestinal apolipoprotein B mRNA editing levels by a zinc-deficient diet and CDNA cloning of editing protein in hamsters. J Nutr. 2000;130(9):2166-73. https://doi.org/10.1093/jn/130.9.2166.

27. Moslehi A, Hamidi-Zad Z. Role of SREBPs in liver diseases: a mini-review. J Clin Transl Hepatol. 2018;6(3):332-8. https://doi.org/10.14218/JCTH.2017. 00061.

28. Guo S, Li L, Yin H. Cholesterol homeostasis and liver $X$ receptor $(\mathrm{LXR})$ in atherosclerosis. Cardiovasc Hematol Disord Drug Targets. 2018;18(1):27-33. https://doi.org/10.2174/1871529X18666180302113713.

29. Yang HX, Zhang M, Long SY, Tuo QH, Tian Y, Chen JX, et al. Cholesterol in LDL receptor recycling and degradation. Clin Chim Acta. 2020;500:81-6. https://doi.org/10.1016/j.cca.2019.09.022.
30. Ge MX, Shao RG, He HW. Advances in understanding the regulatory mechanism of cholesterol 7a-hydroxylase. Biochem Pharmacol. 2019;164: 152-64. https://doi.org/10.1016/j.bcp.2019.04.008.

31. Kidambi S, Patel SB. Cholesterol and non-cholesterol transporters: ABCG5, ABCG8 and NPC1L1: a review. Xenobiotica. 2008;38(7-8):1119-39. https:// doi.org/10.1080/00498250802007930.

32. Pramfalk C, Jiang ZY, Parini P. Hepatic Niemann-pick C1-like 1. Curr Opin Lipidol. 2011;22(3):225-30. https://doi.org/10.1097/MOL.0b013e3283468c28

33. Davis HR, Veltri EP. Zetia: inhibition of Niemann-pick C1 like 1 (NPC1L1) to reduce intestinal cholesterol absorption and treat hyperlipidemia. J Atheroscler Tromb. 2007;14(3):99-108. https://doi.org/10.5551/jat.14.99.

34. Ge L, Wang J, Qi W, Miao HH, Cao J, Qu YX, et al. The cholesterol absorption inhibitor ezetimibe acts by blocking the sterol-induced internalization of NPC1L1. Cell Metab. 2008;7(6):508-19. https://doi.org/10.1 016/j.cmet.2008.04.001.

35. Schreiber $\mathrm{R}$, Xie H, Schweiger M. Of mice and men: the physiological role of adipose triglyceride lipase (ATGL). Biochim. Biophys. Acta Mol Cell Biol Lipids. 2019;1864(6):880-99. https://doi.org/10.1016/j.bbalip.2018.10.008.

36. Ma B, Jia J, Wang X, Zhang R, Niu S, Ni L, et al. Differential roles of scavenger receptor class $B$ type I: a protective molecule and a facilitator of atherosclerosis (review). Mol Med Rep. 2020;22(4):2599-604. https://doi.org/1 0.3892/mmr.2020.11383

37. Lin P, Yin F, Shen N, Liu N, Zhang B, Li Y, et al. Integrated bioinformatics analysis of the anti-atherosclerotic mechanisms of the polysaccharide CM1 from Cordyceps militaris. Int J Biol Macromol. 2021. https://doi.org/10.1016/j. ijbiomac.2021.10.175.

38. Cucuianu M, Coca M, Hâncu N. Reverse cholesterol transport and atherosclerosis. A mini review. Rom. J Intern Med. 2007:45(1):17-27.

39. Yamaguchi Y, Kagota S, Nakamura K, Shinozuka K, Kunitomo M. Inhibitory effects of water extracts from fruiting bodies of cultured Cordyceps sinensis on raised serum lipid peroxide levels and aortic cholesterol deposition in atherosclerotic mice. Phytother Res. 2000;14(8):650-2. https://doi.org/10. 1002/1099-1573(200012)14:8<650::AID-PTR675>3.0.CO;2-0.

40. Catry E, Pachikian BD, Salazar N, Neyrinck AM, Cani PD, Delzenne NM. Ezetimibe and simvastatin modulate gut microbiota and expression of genes related to cholesterol metabolism. Life Sci. 2015;132:77-84. https:// doi.org/10.1016/j.lfs.2015.04.004.

41. Engelking LJ, McFarlane MR, Li CK, Liang G. Blockade of cholesterol absorption by ezetimibe reveals a complex homeostatic network in enterocytes. J Lipid Res. 2012;53(7):1359-68. https://doi.org/10.1194/jlr.M02 7599.

42. Xu RX, Liu J, Li XL, Li S, Zhang Y, Jia YJ, et al. Impacts of ezetimibe on PCSK9 in rats: study on the expression in different organs and the potential mechanisms. J Transl Med. 2015;13(1):87. https://doi.org/10.1186/s12967-01 5-0452-x.

43. Nakano T, Inoue I, Takenaka Y, Ito R, Kotani N, Sato S, et al. Ezetimibe impairs transcellular lipid trafficking and induces large lipid droplet formation in intestinal absorptive epithelial cells. Biochim. Biophys. Acta Mol Cell Biol Lipids. 2020;1865(12):158808.

44. Telford DE, Sutherland BG, Edwards JY, Andrews JD, Barrett PH, Huff MW. The molecular mechanisms underlying the reduction of LDL apoB-100 by ezetimibe plus simvastatin. J Lipid Res. 2007;48(3):699-708. https://doi.org/1 0.1194/jlr.M600439-JLR200.

45. Naples M, Baker C, Lino M, lqbal J, Hussain MM, Adeli K. Ezetimibe ameliorates intestinal chylomicron overproduction and improves glucose tolerance in a diet-induced hamster model of insulin resistance. Am J Physiol Gastrointest Liver Physiol. 2012;302(9):G1043-52. https://doi.org/1 0.1152/ajpgi.00250.2011.

46. Wang X, Ren Q, Wu T, Guo Y, Liang Y, Liu S. Ezetimibe prevents the development of non-alcoholic fatty liver disease induced by high-fat diet in C57BL/6J mice. Mol Med Rep. 2014;10(6):2917-23. https://doi.org/10.3892/ mmr.2014.2623.

47. Shimada M, Shimano H, Gotoda T, Yamamoto K, Kawamura M, Inaba T, et al. Overexpression of human lipoprotein lipase in transgenic mice. Resistance to diet-induced hypertriglyceridemia and hypercholesterolemia. J Biol Chem. 1993;268(24):17924-9. https://doi.org/10.1016/S0021-9258(17)4 6793-7.

48. Kitajima S, Morimoto M, Liu E, Koike T, Higaki Y, Taura Y, et al. Overexpression of lipoprotein lipase improves insulin resistance induced by a high-fat diet in transgenic rabbits. Diabetologia. 2004;47(7):1202-9. https:// doi.org/10.1007/s00125-004-1429-0. 
49. Poulsen LI, Siersbæk M, Mandrup S. PPARs: fatty acid sensors controlling metabolism. Semin Cell Dev Biol. 2012;23(6):631-9. https://doi.org/10.1016/j. semcdb.2012.01.003.

50. Amirullah NA, Zainal Abidin N, Abdullah N. The potential applications of mushrooms against some facets of atherosclerosis: a review. Food Res Int. 2018;105:517-36. https://doi.org/10.1016/j.foodres.2017.11.023.

51. Zhong D, Xie Z, Huang B, Zhu S, Wang G, Zhou H, et al. Ganoderma lucidum polysaccharide peptide alleviates hepatoteatosis via modulating bile acid metabolism dependent on FXR-SHP/FGF. Cell Physiol Biochem. 2018;49(3):1163-79. https://doi.org/10.1159/000493297.

52. Wang $X$, Shi L, Joyce $S$, Wang $Y$, Feng $Y$. MDG-1, a potential regulator of PPARa and PPARY, ameliorates dyslipidemia in mice. Int J Mol Sci. 2017; 18(9):1930. https://doi.org/10.3390/ijms18091930.

53. Yang Z, Liu G, Wang Y, Yin J, Wang J, Xia B, et al. Fucoidan A2 from the brown seaweed Ascophyllum nodosum lowers lipid by improving reverse cholesterol transport in C57BL/6J mice fed a high-fat diet. J Agric Food Chem. 2019;67(20):5782-91. https://doi.org/10.1021/acs.jafc.9b01321.

54. Liu Q, Siloto RM, Lehner R, Stone SJ, Weselake RJ. Acyl-CoA: diacylglycerol acyltransferase: molecular biology, biochemistry and biotechnology. Prog Lipid Res. 2012;51(4):350-77. https://doi.org/10.1016/j.plipres.2012.06.001.

55. Jin L, Shi $X$, Yang J, Zhao $Y, X u e ~ L, X u ~ L$, et al. Gut microbes in cardiovascular diseases and their potential therapeutic applications. Protein Cell. 2021;12(5):346-59. https://doi.org/10.1007/s13238-020-00785-9.

56. Romero-Córdoba SL, Salido-Guadarrama I, Meneses ME, Cosentino G, lorio MV, Tagliabue E, et al. Mexican Ganoderma Lucidum extracts decrease lipogenesis modulating transcriptional metabolic networks and gut microbiota in C57BL/6 mice fed with a high-cholesterol diet. Nutrients. 2020;13(1):38. https://doi.org/10.3390/nu13010038.

\section{Publisher's Note}

Springer Nature remains neutral with regard to jurisdictional claims in published maps and institutional affiliations.

Ready to submit your research? Choose BMC and benefit from:

- fast, convenient online submission

- thorough peer review by experienced researchers in your field

- rapid publication on acceptance

- support for research data, including large and complex data types

- gold Open Access which fosters wider collaboration and increased citations

- maximum visibility for your research: over $100 \mathrm{M}$ website views per year

At $\mathrm{BMC}$, research is always in progress.

Learn more biomedcentral.com/submissions 